PAPER • OPEN ACCESS

Temperature-dependent near-surface interstitial segregation in niobium

To cite this article: Guilherme Dalla Lana Semione et al 2021 J. Phys.: Condens. Matter 33265001

View the article online for updates and enhancements.

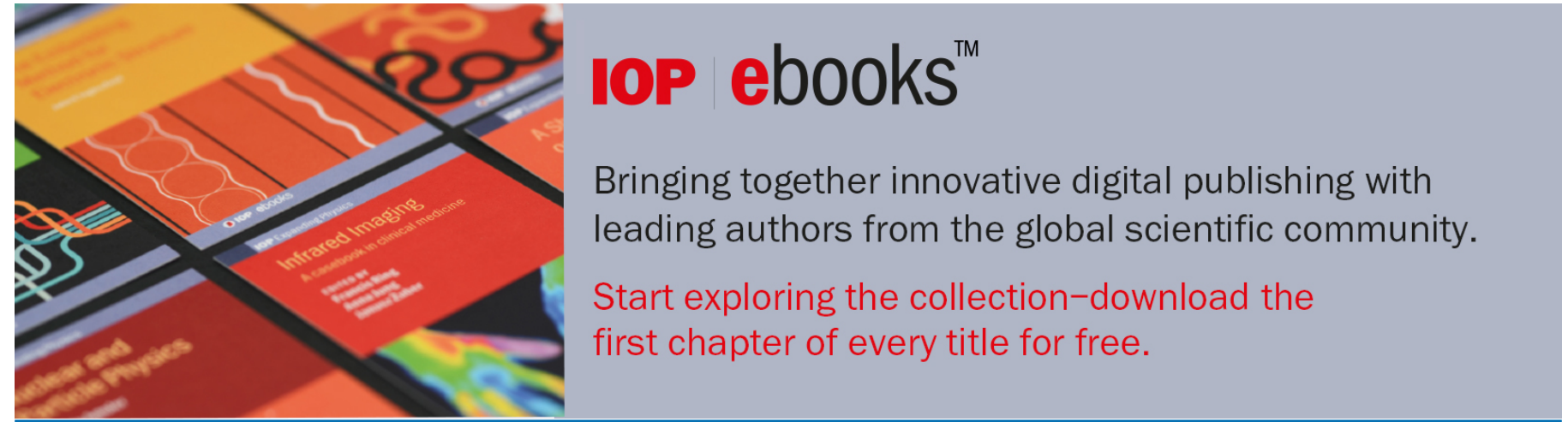

This content was downloaded from IP address 131.169 .254 .6 on $04 / 08 / 2021$ at $13: 25$ 


\title{
Temperature-dependent near-surface interstitial segregation in niobium
}

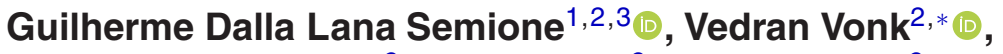 \\ Arti Dangwal Pandey ${ }^{2}$, Elin Grånäs ${ }^{2}$, Björn Arndt ${ }^{2}$, Marc Wenskat ${ }^{2}$, \\ Wolfgang Hillert ${ }^{1}$, Heshmat Noei $^{2}$ and $\odot$ Andreas Stierle ${ }^{1,2} \odot$ \\ ${ }^{1}$ Fachbereich Physik, Universität Hamburg, 22607 Hamburg, Germany \\ 2 Deutsches Elektronen-Synchrotron DESY, 22607 Hamburg, Germany \\ E-mail: vedran.vonk@desy.de
}

Received 11 January 2021, revised 1 March 2021

Accepted for publication 20 April 2021

Published 24 May 2021

\begin{abstract}
Niobium's superconducting properties are affected by the presence and precipitation of impurities in the near-surface region. A systematic wide-temperature range $\mathrm{x}$-ray diffraction study is presented addressing the effect of low temperatures $(108 \mathrm{~K}-130 \mathrm{~K})$ and annealing treatments ( $523 \mathrm{~K}$ in nitrogen atmosphere, $400 \mathrm{~K}$ in UHV) on the near-surface region of a hydrogen-loaded $\mathrm{Nb}(100)$ single-crystal. Under these conditions, the response of the natural surface oxides $\left(\mathrm{Nb}_{2} \mathrm{O}_{5}, \mathrm{NbO}_{2}\right.$, and $\left.\mathrm{NbO}\right)$ and the changes in the subsurface concentration of interstitial species in $\mathrm{Nb}$ are explored, thereby including the cryogenic temperature regime relevant for device operation. The formation and suppression of niobium hydrides in such conditions are also investigated. These treatments are shown to result in: (i) an increase in the concentration of interstitial species (oxygen and nitrogen) occupying the octahedral sites of the $\mathrm{Nb}$ bcc lattice at room temperature, both in the near-surface region and in the bulk. (ii) A decrease in the concentration of interstitials within the first $10 \mathrm{~nm}$ from the surface at $130 \mathrm{~K}$. (iii) Hydride formation suppression at temperatures as low as $130 \mathrm{~K}$. These results show that mild annealing in nitrogen atmosphere can suppress the formation of superconducting-detrimental niobium hydrides, while subsurface interstitial atoms tend to segregate towards the surface at $130 \mathrm{~K}$, therefore altering the local concentration of impurities within the RF penetration depth of $\mathrm{Nb}$. These processes are discussed in the context of the improvement of niobium superconducting radio-frequency cavities for next-generation particle accelerators.
\end{abstract}

Keywords: niobium surface, interstitials, structure

S Supplementary material for this article is available online

(Some figures may appear in colour only in the online journal)

\footnotetext{
${ }^{3}$ Present address: University of Bremen, MAPEX Core Facility for Materials Analytics, MAPEX Center for Materials and Processes, 28334 Bremen, Germany.

* Author to whom any correspondence should be addressed.

(c) (i) Original content from this work may be used under the terms of the Creative Commons Attribution 4.0 licence. Any further distribution of this work must maintain attribution to the author(s) and the title of the work, journal citation and DOI.
}

\section{Introduction}

Niobium is a type II superconductor with the highest critical transition temperature $\left(T_{\mathrm{c}}\right)$ of all pure metals. Owing to its favorable mechanical properties, it is the current material of choice for large scale superconducting applications [1]. Its superconducting properties are primarily affected by impurities and defects, which may alter $T_{\mathrm{c}}$ or the flux pinning abilities [2-5]. Such impurities can be present as interstitials or 
may precipitate, thereby also changing the metal's mechanical stability $[6,7]$. The most prominent and often unavoidable species entering the $\mathrm{Nb}$ matrix are oxygen and hydrogen, whereby the former forms a native oxide on the surface, and the latter forms niobium hydrides when cooling to cryogenic temperatures $[8,9]$. The concentration of these species depends on their availability, temperature-dependent solubility, and materials processing history, which can kinetically hinder the $\mathrm{Nb}$ matrix of locally reaching saturation levels, leading to concentration gradients. The understanding and control of these processes are essential for superconducting applications based on niobium.

In the field of particle accelerators, superconducting radiofrequency (SRF) $\mathrm{Nb}$ cavities are an enabling technology. For the next-generation accelerators, the operation of such $\mathrm{Nb}$ cavities at high electric field gradients require a high quality factor, $Q_{0}$. The fabrication of these cavities is a complex process consisting of many steps $[10,11]$. However, it has been found that annealing treatments in controlled gas environments of the final device may lead to drastic improvements in $Q_{0}$. In particular, the baking of the cavities in a pure nitrogen atmosphere has been reported to have a positive effect, attributed to the possible unproved suppression of detrimental hydride formation when cooling the device into its superconducting state [12-15]. The uptake of hydrogen is unavoidable during the fabrication, in particular during polishing steps of standard cavity preparations such as electropolishing (EP), buffered chemical polishing (BCP), and centrifugal barrel polishing $(\mathrm{CBP})$ in water solution $[8,16]$. This unwanted effect is even enhanced when the natural oxide layer is partially removed from the surface $[1,17,18]$. Hydrogen atoms randomly occupy the tetrahedral sites of the $\mathrm{Nb}$ bcc lattice up to their solubility limit, which amounts to $\approx 4 \%$ at room temperature [19-21]. Upon cooldown, niobium-hydride phases will precipitate $[8,14]$, which for SRF cavities are generally linked to severe degradations of $Q_{0}$ such as the so-called ' $\mathrm{Q}$ disease' - an anomalous loss mechanism manifested as a lowfield $Q_{0}$ which even decreases exponentially above $1 \mathrm{MV} \mathrm{m}^{-1}$ [18], and the high field Q-slope (HFQS) - a sharp increase in RF losses above a peak magnetic field of about $90 \mathrm{mT}[1,15$, 17]. These degradations are partly due to the hydrides having a much lower $T_{\mathrm{c}}$ (1.8 K [22]) than the pure $\mathrm{Nb}$ matrix $(9.25 \mathrm{~K})$. The Q-disease can be cured by high-vacuum annealing above $873 \mathrm{~K}$ for a few hours and the HFQS between 373-393 K for more extended periods (24 to $48 \mathrm{~h}$ ) [14, 17]. Also, interstitial oxygen and nitrogen were discussed to result in active trapping sites for hydrogen atoms, thereby suppressing the formation of niobium hydrides $[15,19,23,24]$. This may also explain why annealing under controlled nitrogen atmospheres, such as the so-called nitrogen doping ( $T=1073-1273 \mathrm{~K}$ ) and nitrogen infusion $(T=393-433 \mathrm{~K})$ treatments, aimed to increase the presence of interstitial nitrogen in the nearsurface region of $\mathrm{Nb}$, can drastically improve $Q_{0}[12,13]$. Furthermore, the presence of interstitial nitrogen in the nearsurface region of $\mathrm{Nb}$ SRF cavities, allied with the shrinkage of the natural oxides during high-temperature annealing cycles, was reported to increase its superconducting energy gap while significantly reducing its RF surface resistance $\left(R_{\mathrm{S}}\right)[25,26]$.
The superconducting properties of $\mathrm{Nb}$ were reported to be severely affected by the precipitation of different phases and the presence of interstitial impurities. Studies performed on $\mathrm{Nb}$ specimens, which with minimal impurity concentration display a $T_{c}$ of $9.46 \mathrm{~K}$, indicated that an oxygen concentration $c_{\text {oxygen }}=3.83$ at. $\%$ lowers $T_{\mathrm{c}}$ to $5.84 \mathrm{~K}$, while reaching $9.02 \mathrm{~K}$ when $c_{\text {oxygen }}=6.43$ at. $\%$. Increases in nitrogen and hydrogen concentrations $c_{\text {nitrogen }}$ and $c_{\text {hydrogen }}$ below the solubility limit of the $\mathrm{Nb}(\mathrm{H}, \mathrm{N})$ solid solutions was reported to slightly affect $T_{\mathrm{c}}$, displaying values of $9.12 \mathrm{~K}$ when $c_{\text {nitrogen }}=0.33$ at. $\%$ and $9.22 \mathrm{~K}$ when $c_{\text {hydrogen }}=3.6$ at.\% [2]. Although having little effect on $T_{\mathrm{c}}$, the presence of interstitial hydrogen in the $\mathrm{Nb}$ matrix strongly affects its normal electrical resistance, which increases with $c_{\text {hydrogen }}$ and is virtually temperature independent, unless the precipitation of niobium hydrides takes place [27]. The critical current density and the critical field of $\mathrm{Nb}$ are also reported to increase with the concentration of impurities. For example, the upper critical field $\mathrm{H}_{c 2}$ was reported to increase from $2.7 \mathrm{kOe}$ to $9.6 \mathrm{kOe}$ when $c_{\text {oxygen }}=1.52$ at. $\%$ [28, 29].

Recently, SRF Nb cavities surged a viable option for 3D circuit quantum electrodynamics (QED) architectures due to their high $Q_{0}$ when compared to regular 3D resonators [30, 31]. One major challenge for the further development of quantum computing lies in the control over the decoherence, which is the loss of the qubits' quantum states [32]. The extremely high Q-factors of niobium SRF cavities, may help in overcoming this issue and first demonstrations have shown that typical coherence times may be enhanced by orders of magnitude [33]. Therefore, there is an additional interest in transferring the knowledge obtained from SRF cavity research and development to quantum information processing. This especially accounts for the materials science aspects related to impurities, which for the typical processing recipes have only recently begun to be studied in bulk crystals. Niobium thin films, on the other hand, have been used in quantum computing already and the role of impurities has been elucidated [34]. It was found that the performance of superconducting quantum interference device (SQUID) qubits is extremely sensitive to the amount and distribution of impurities, especially due to its induced changes on the gap voltage of $\mathrm{Nb}$ films based Josephson junctions [34]. For example, oxygen diffusion from $\mathrm{Al}_{2} \mathrm{O}_{3}$ substrates into $\mathrm{Nb}$ films in $\mathrm{Al}_{2} \mathrm{O}_{3} / \mathrm{Nb}$ Josephson junctions has been reported as a potential source of noise in such devices [35].

Here, a study is presented systematically following the structure of the $\mathrm{Nb}$ near-surface region when subjected to typical processing conditions of Nb SRF cavities. To rule out as much as possible the influence of species other than $\mathrm{O}$, $\mathrm{N}$, and $\mathrm{H}$, the $\mathrm{Nb}(100)$ single crystals were first made ultraclean up to deep in the bulk. The samples were then loaded with hydrogen by exposure to clean hydrogen gas at elevated temperature. These samples were then characterized at different temperatures using grazing-incidence x-ray diffraction (GIXRD), thereby probing the near-surface region and revealing the details of the natural oxide layer, hydride formation, and the interstitial distribution. The hydride formation is further correlated with the consumption of the natural oxides 
$\mathrm{Nb}_{2} \mathrm{O}_{5}, \mathrm{NbO}_{2}$ and $\mathrm{NbO}$ and the distribution of subsurface interstitials in $\mathrm{Nb}$. Complementary atomic force microscopy (AFM) measurements supporting the GIXRD observations are also discussed.

\section{Experiment}

The mechanically polished niobium (100) single-crystals (10 $\mathrm{mm}$ diameter, $2 \mathrm{~mm}$ height, oriented better than $0.1^{\circ}$ ) employed in this work were pre-annealed at $2273 \mathrm{~K}$ for $6 \mathrm{~h}$ by induction heating in an ultrahigh vacuum (UHV) furnace with an initial pressure of $\sim 10^{-10}$ mbar. Afterwards, the samples were unavoidably exposed to air for several days.

In situ $\mathrm{x}$-ray reflectivity (XRR) and grazing-incidence $\mathrm{x}$ ray diffraction (GIXRD) measurements were performed during the hydrogen loading with a photon energy of $8.04 \mathrm{keV}(\mathrm{Cu}$ $\mathrm{K}-\alpha$ ). For the cooling and annealing experiments, in situ $\mathrm{x}$-ray diffuse scattering, GIXRD, and XRR measurements were performed with a photon energy of $15 \mathrm{keV}$ at the beamline ID03 at the European synchrotron radiation facility (ESRF) in Grenoble, France. The UHV chamber present at the ID03 beamline (base pressure of $5 \times 10^{-11}$ mbar) was equipped with a boron nitride heater and a liquid nitrogen-cooled cryostat. This enabled the temperature of the samples to vary from $1400 \mathrm{~K}$ down to $130 \mathrm{~K}$. For the thermal treatments involving nitrogen presence, nitrogen gas with a purity of $99.999 \%$ was inserted into the chamber through a leak valve until the system reached a pressure of $3.3 \times 10^{-2}$ mbar. The chamber valves were then closed, leaving the sample in a static nitrogen atmosphere. The sequence of temperature points was chosen such that the initial hydrogen-loaded samples were first measured at room temperature and then cooled to $130 \mathrm{~K}$, which revealed the formation of hydrides. The samples were then annealed at $523 \mathrm{~K}$ in a nitrogen environment, which resembles the previously mentioned nitrogen infusion treatment of SRF cavities. After this annealing step, the samples were again characterized at room temperature and then at $130 \mathrm{~K}$, whereby hydrides could no longer be detected.

The complementary atomic force microscopy (AFM) measurements were performed using a commercial variable temperature scanning probe microscope in contact mode with the samples mounted in a UHV chamber having a base pressure 5 $\times 10^{-10}$ mbar. The samples were cooled using a liquid nitrogen bath cryostat, with the lowest temperature reaching $108 \mathrm{~K}$.

The total processing scheme and characterization steps, using different techniques, is shown in figure 1.

\section{Results}

\subsection{Hydrogen loading}

The $\mathrm{Nb}(100)$ samples were placed inside the in situ UHV chamber operating with a base pressure of $\approx 5 \times 10^{-9}$ mbar. The hydrogen annealing consisted in a sequential treatment starting at $393 \mathrm{~K}$ under a $\mathrm{H}_{2}$ pressure of $1 \times 10^{-6}$ mbar which was later increased to $1 \times 10^{-5}$ mbar and finally to $1 \times 10^{-4}$ mbar. In this final step the temperature was increased to $423 \mathrm{~K}$ while the $\mathrm{H}_{2}$ pressure was kept constant (see also appendix A).

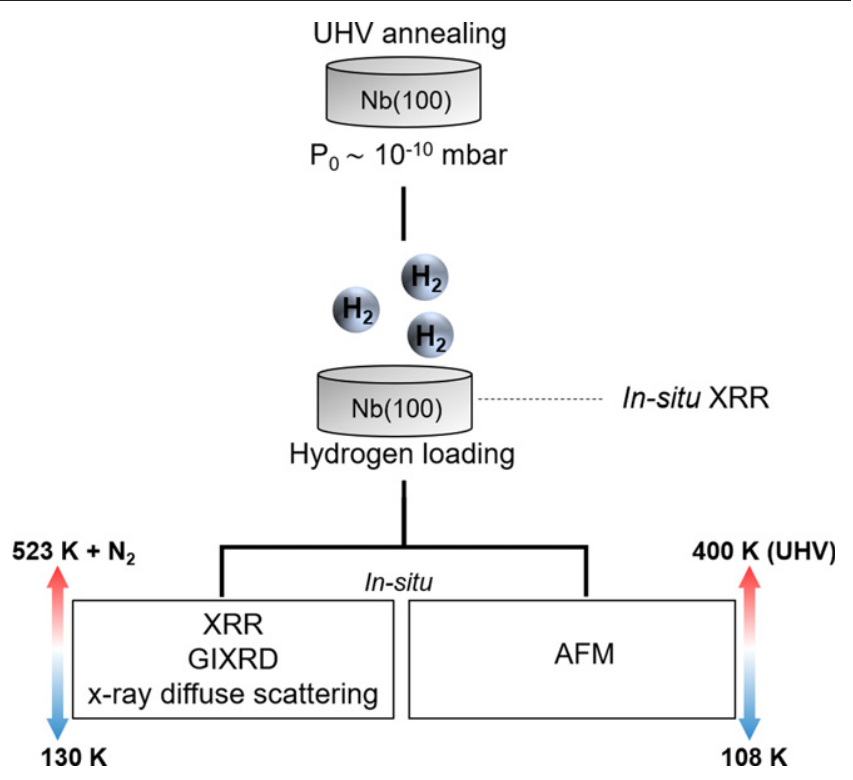

Figure 1. Schematic view of the sample processing and measurements. $\mathrm{Nb}(100)$ single-crystals were first made ultra-clean by prolonged high temperature annealing in UHV. Then they were loaded with hydrogen, the process details of which are listed in appendix A. During further annealing and cooling treatments, using different gas environments, the samples were characterized by $\mathrm{x}$-ray scattering techniques and AFM.

At this stage, the solubility limit of hydrogen in $\mathrm{Nb}$ is $\approx 15 \%$ and the maximal hydrogen concentration expected in respect to the $\mathrm{H}_{2}$ pressure is close to $\approx 3$ at $\%$ [21].

In situ XRR measurements and the respective obtained electron density profiles before and after the loading are shown in Figures 2(a) and (b). All XRR curves discussed here were fitted using the Parrat formalism [36, 37], taking into account finite resolution effects [38]. Initially, the surface shows the typical natural oxide composition of $\mathrm{Nb}_{2} \mathrm{O}_{5}, \mathrm{NbO}_{2}$, and $\mathrm{NbO}$ from the surface to the oxide/metal interface, with thicknesses of $0.9,0.8$ and $0.7 \mathrm{~nm}$, respectively. The total oxide thickness amounts to $2.4 \pm 0.1 \mathrm{~nm}$. The hydrogen loading procedure only slightly affected the surface oxide layer thickness, while maintaining the same configuration $\left(\mathrm{Nb}_{2} \mathrm{O}_{5}, \mathrm{NbO}_{2}\right.$, and $\left.\mathrm{NbO}\right)$. At the end of the hydrogen loading, the total oxide thickness reached $2.1 \pm 0.1 \mathrm{~nm}$, with individual thicknesses of $0.8,0.7$, and $0.6 \mathrm{~nm}$ for $\mathrm{Nb}_{2} \mathrm{O}_{5}, \mathrm{NbO}_{2}$, and $\mathrm{NbO}$, respectively. All retrieved roughness values, before and after the loading, remained in a similar range between 0.1 and $0.4 \mathrm{~nm}$. Table SI, available in the supplementary material (https://stacks.iop.org/JPCM/33/265001/mmedia), describes the temperature, annealing time and $\mathrm{H}_{2}$ pressure during each step of the process. Based on the temperature and pressure of the hydrogen treatment, the hydrogen concentration was estimated to be 1 at.\% at the end of the thermal treatment [21]. In agreement with such estimation, figure 2(c) presents selected GIXRD scans through the $(211) \mathrm{Nb}$ reflection at a fixed incident angle $\alpha_{i}=0.5^{\circ}$ corresponding to a scattering depth $\Lambda_{\mathrm{e}}$ of $\approx 85 \mathrm{~nm}$ before and after the complete loading experiment, with both measurements obtained at room temperature. A slight change in the peak position to lower $H$ values determined by fitting corresponding pseudo-Voigt 


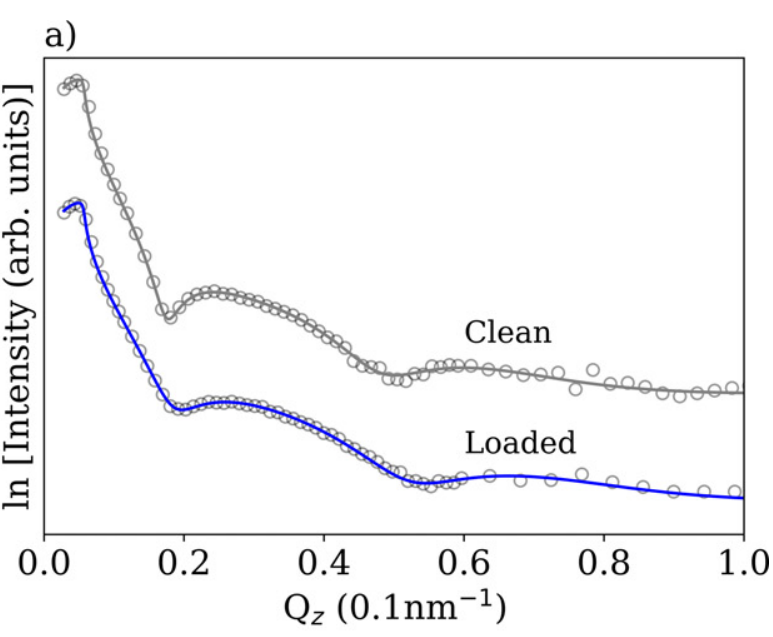

b)

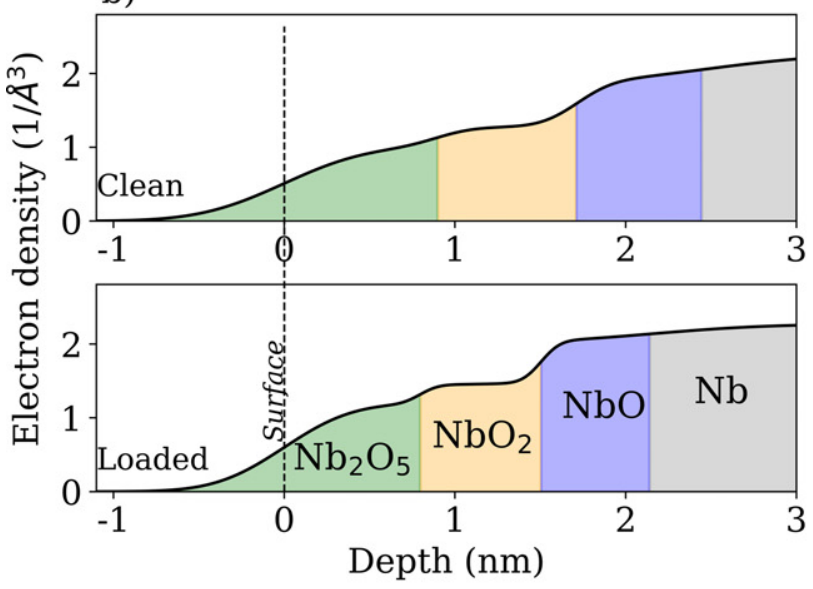

C)

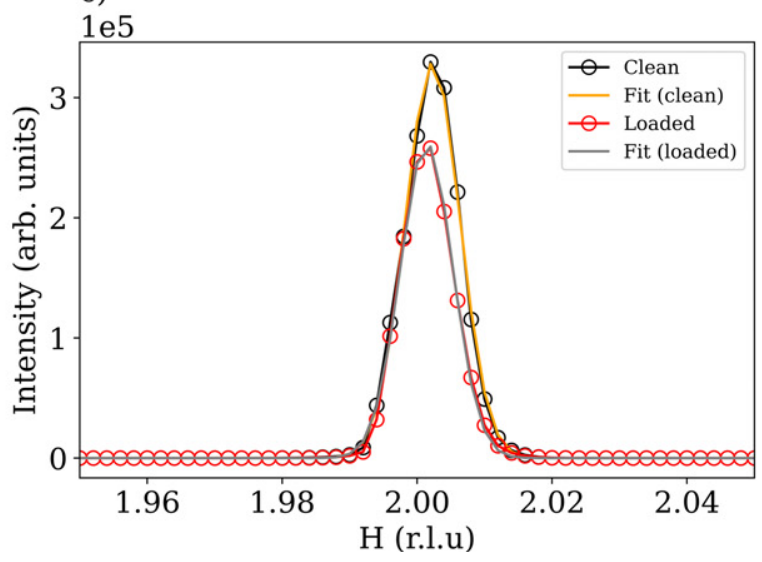

Figure 2. X-ray reflectivity data (a), electron density profiles (b) and GIXRD scans through the (211) Nb Bragg peak with their respective fits (c) obtained before and after the hydrogen loading. All measurements were performed at room temperature.

components is observed after the hydrogen loading, indicating an increase of $0.06 \%$ in the lattice parameter $a_{\text {lat }}$ of $\mathrm{Nb}$. When assuming that this change is only due to interstitial hydrogen in the $\mathrm{Nb}$ matrix, a hydrogen concentration of $1.0 \pm 0.5$ at. $\%$ is retrieved [39].
3.2. Effect of low temperatures on the natural oxides studied by in situ XRR

In order to follow the effects of the cryogenic temperatures as well as of the thermal treatments on the natural oxides present at the surface of $\mathrm{Nb}(100)$, XRR measurements were performed in situ at different stages of the experiment as shown in figures 3(a) and (c) while its corresponding extracted electron density profiles are displayed in figures 3(b) and (d). Following previous studies of $\mathrm{Nb}(100)$ and (110) surfaces, the best fits for the collected XRR data were obtained when assuming an increase in the electron density from the surface to the oxide/metal interface, which is recognized as the ordering $\mathrm{Nb}_{2} \mathrm{O}_{5}, \mathrm{NbO}_{2}$ and $\mathrm{NbO}$ on top of the $\mathrm{Nb}$ crystal (since the respective bulk electron densities follow $\mathrm{Nb}_{2} \mathrm{O}_{5}<\mathrm{NbO}_{2}<$ $\mathrm{NbO}<\mathrm{Nb}$ ) [40, 41]. The calculated bulk electron density values for the oxides are depicted in figures 3(b) and (d). After oxygen adsorption, the formation of $\mathrm{NbO}$ is recognized as the first oxidation step of $\mathrm{Nb}[42,43]$. Following larger oxygen exposures, the formation of $\mathrm{NbO}_{2}$ and $\mathrm{Nb}_{2} \mathrm{O}_{5}$ takes place [44], in agreement with the model proposed here. The detailed optimized fit parameters are listed in appendix B.

At room temperature, prior to the $\mathrm{N}_{2}$ annealing, the typical composition obtained with the air oxidation of $\mathrm{Nb}$ specimens is observed with the presence of $\mathrm{Nb}_{2} \mathrm{O}_{5}, \mathrm{NbO}_{2}$ and $\mathrm{NbO}$, displaying thicknesses of 1.2, 0.9 , and $0.6 \mathrm{~nm}$ respectively, combining to a total of $2.7 \pm 0.1 \mathrm{~nm}$. The roughness of the individual interfaces was $0.3,0.2$, and $0.2 \mathrm{~nm}$, while the substrate displayed an atomically smooth surface with an associated roughness of $0.1 \mathrm{~nm}$.

As the sample was cooled to $130 \mathrm{~K}$ the observed XRR changed, as highlighted in the inset of figure 3(a), which presents the difference between the normalized XRR data obtained at room temperature and at $130 \mathrm{~K}$. The combination between the scatterer's (the natural oxide layer) thickness and its electron density can qualitatively explain the measured signal. As the temperature was lowered to $130 \mathrm{~K}$, the amplitude of the reflected intensity clearly increased while the oscillation periods remained similar, suggesting no change in the thickness of the oxide layer, but only in its electron density. However, a quantitative approach using the Parrat formalism yields an increase in the thickness of $\mathrm{Nb}_{2} \mathrm{O}_{5}$ and $\mathrm{NbO}$ layers to 1.3 and $0.8 \mathrm{~nm}$, while $\mathrm{NbO}_{2}$ decreased to $0.8 \mathrm{~nm}$. The associated roughnesses of $0.3,0.2$, and $0.3 \mathrm{~nm}$ for the vacuum/ $\mathrm{Nb}_{2} \mathrm{O}_{5}$, $\mathrm{Nb}_{2} \mathrm{O}_{5} / \mathrm{NbO}_{2}$ and $\mathrm{NbO}_{2} / \mathrm{NbO}$ interfaces were also retrieved from the analysis. At this stage, the sample showed a total oxide thickness of $2.9 \pm 0.1 \mathrm{~nm}$, while the roughness of the oxide/metal interface remained constant. Moreover, a reduction in the retrieved electron densities of $\mathrm{Nb}_{2} \mathrm{O}_{5}$ and $\mathrm{NbO}_{2}$ is observed upon cooling to $130 \mathrm{~K}$, meanwhile the electron density of $\mathrm{NbO}$, the closest oxide to the oxide/metal interface, increased (see table SII in the supplementary material). The observed changes in the electron density and thickness of the natural oxides can be explained by a segregation of the available subsurface interstitial oxygen towards the surface upon cooldown. Such effect increases the thickness of $\mathrm{NbO}$, the closest oxide to the oxide/metal interface, in agreement with the $\mathrm{Nb}-\mathrm{O}$ phase diagram [45]. Further oxidation caused by the 

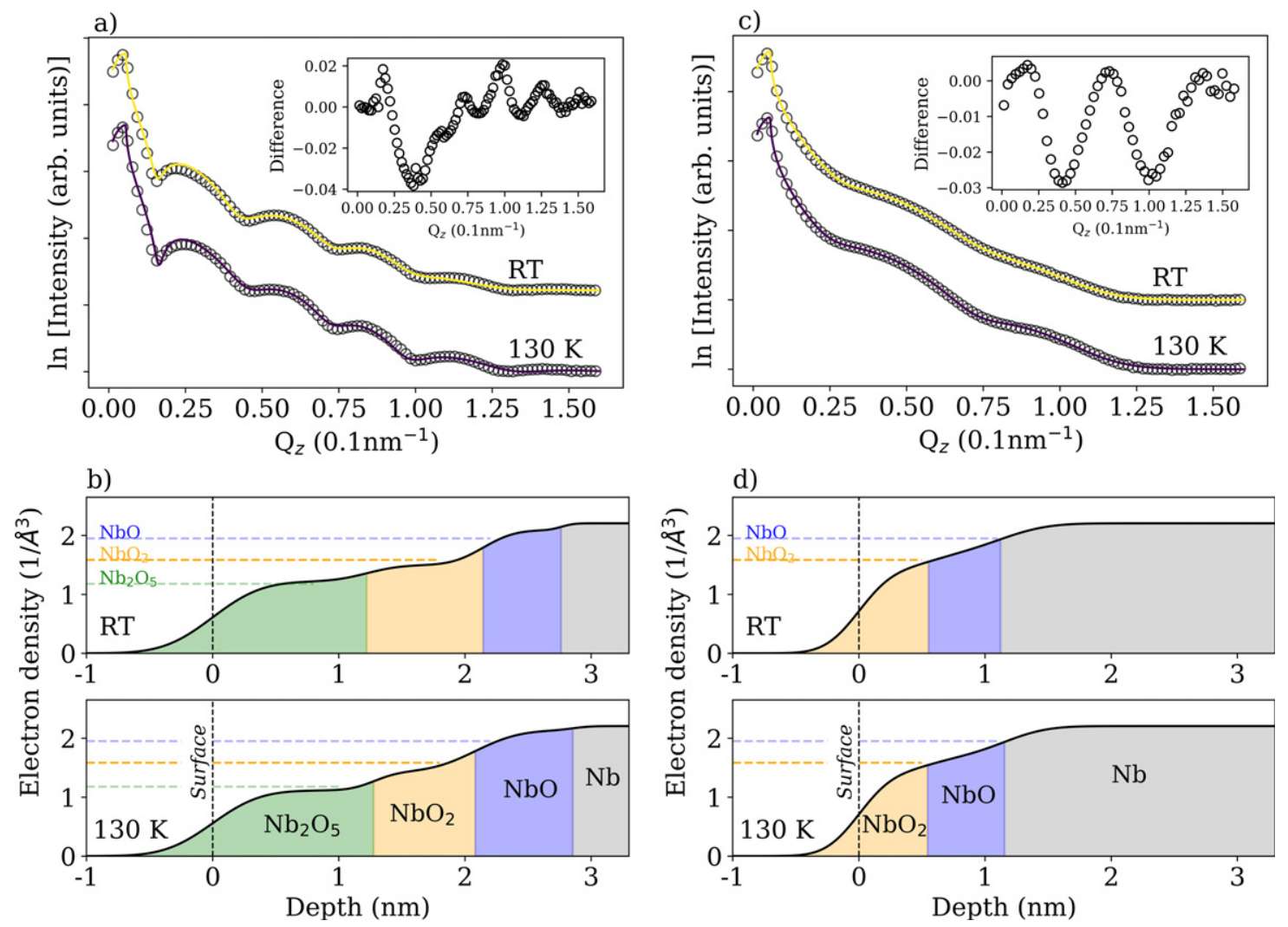

Figure 3. X-ray reflectivity data and the respective electron density profiles obtained at room temperature (RT) and $130 \mathrm{~K}$ for the hydrogen-loaded $\mathrm{Nb}(100)$ sample before (a) and (b) and after the $523 \mathrm{~K}$ annealing in $\mathrm{N}_{2}$ atmosphere (c) and (d). The insets highlight the difference between the curves in logarithmic scale at the two temperatures (RT-130 K), the details of which are discussed in the main text. Before the subtraction, both curves were normalized with respect to the Fresnel reflectivity. The calculated bulk electron density values for the oxides are represented by horizontal dashed lines. Error bars were omitted in all plots. The detailed optimized fit parameters are listed in appendix B.

oxygen segregation leads to the decrease in the electron densities of $\mathrm{NbO}_{2}$ and $\mathrm{Nb}_{2} \mathrm{O}_{5}$, while also affecting the thickness of both oxides. The formation of non-stoichiometric $\mathrm{NbO}_{2+x}$ and $\mathrm{Nb}_{2} \mathrm{O}_{5+x}$ phases due to the promoted oxidation, for example, could help explain the observed lowering in the electron densities of the particular oxides. Effects of adsorbates, such as $\mathrm{H}_{2} \mathrm{O}$, can also be partially responsible for the observed changes of the outmost niobium oxide layer $\left(\mathrm{Nb}_{2} \mathrm{O}_{5}\right)$ upon cooldown. The segregation hypothesis is further explored in the coming sections.

Figure 3(c) shows the XRR measurements (at room temperature and $130 \mathrm{~K}$ ) obtained after annealing the $\mathrm{Nb}$ sample at $523 \mathrm{~K}$ for $1 \mathrm{~h}$ in $\mathrm{N}_{2}$ atmosphere at a pressure of 3.3 $\times 10^{-2}$ mbar while figure $3(\mathrm{~d})$ displays the corresponding electron density profiles. Total consumption of $\mathrm{Nb}_{2} \mathrm{O}_{5}$ was observed after the aforementioned treatment, while the thickness of $\mathrm{NbO}_{2}$ and $\mathrm{NbO}$ decreased considerably, displaying values of $0.5 \mathrm{~nm}$ and $0.6 \mathrm{~nm}$ at room temperature, respectively. Such finding is in agreement with previous studies concerning the stability of the natural oxides of $\mathrm{Nb}$ upon annealing [41, 46-48], irrespective of the presence of $\mathrm{N}_{2}$ [40]. The associated roughness of $0.2 \mathrm{~nm}$ was retrieved for both the vacuum $/ \mathrm{NbO}_{2}$ and $\mathrm{NbO}_{2} / \mathrm{NbO}$ interfaces, while the oxide/metal displayed a roughness of $0.3 \mathrm{~nm}$. The total thickness of the oxide layers drastically reduced by $\approx 1.6 \mathrm{~nm}$ when comparing both stages of the sample at room temperature, before and after the annealing in $\mathrm{N}_{2}$ atmosphere. Meanwhile, no indication of a niobium nitride or nitrogen-rich layer was observed, agreeing with previous studies performed with $\mathrm{Nb}(100)$ single-crystals in similar conditions [40]. Upon cooldown, both $\mathrm{NbO}_{2}$ (now the outmost oxide) and $\mathrm{NbO}$ displayed virtually the same thicknesses, while its associated roughnesses also remained constant when compared to the measurement at room temperature. Similar to the XRR measurements before the nitrogen treatment, the XRR signal shows a higher amplitude at $130 \mathrm{~K}$ when compared to the measurement at room temperature. This is linked with changes in the electron density of the surface oxides, where a slight decrease was observed for $\mathrm{NbO}_{2}$ whereas an increase was detected for $\mathrm{NbO}$. The inset in figure 3(c) shows the difference between the data obtained at room temperature and $130 \mathrm{~K}$, highlighting the aforementioned amplitude differences between the XRR curves. The oscillation periods remained virtually the same at $130 \mathrm{~K}$ and at room temperature, in agreement with the virtually unchanged thickness and roughness of the oxide layers. The electron density, roughness, and thickness values for each oxide during the different steps of the experiment are summarized in tables 2 and 3 shown in appendix $B$.

The observed oxide layer thickness and electron density increase upon cooldown to cryogenic temperatures can be 

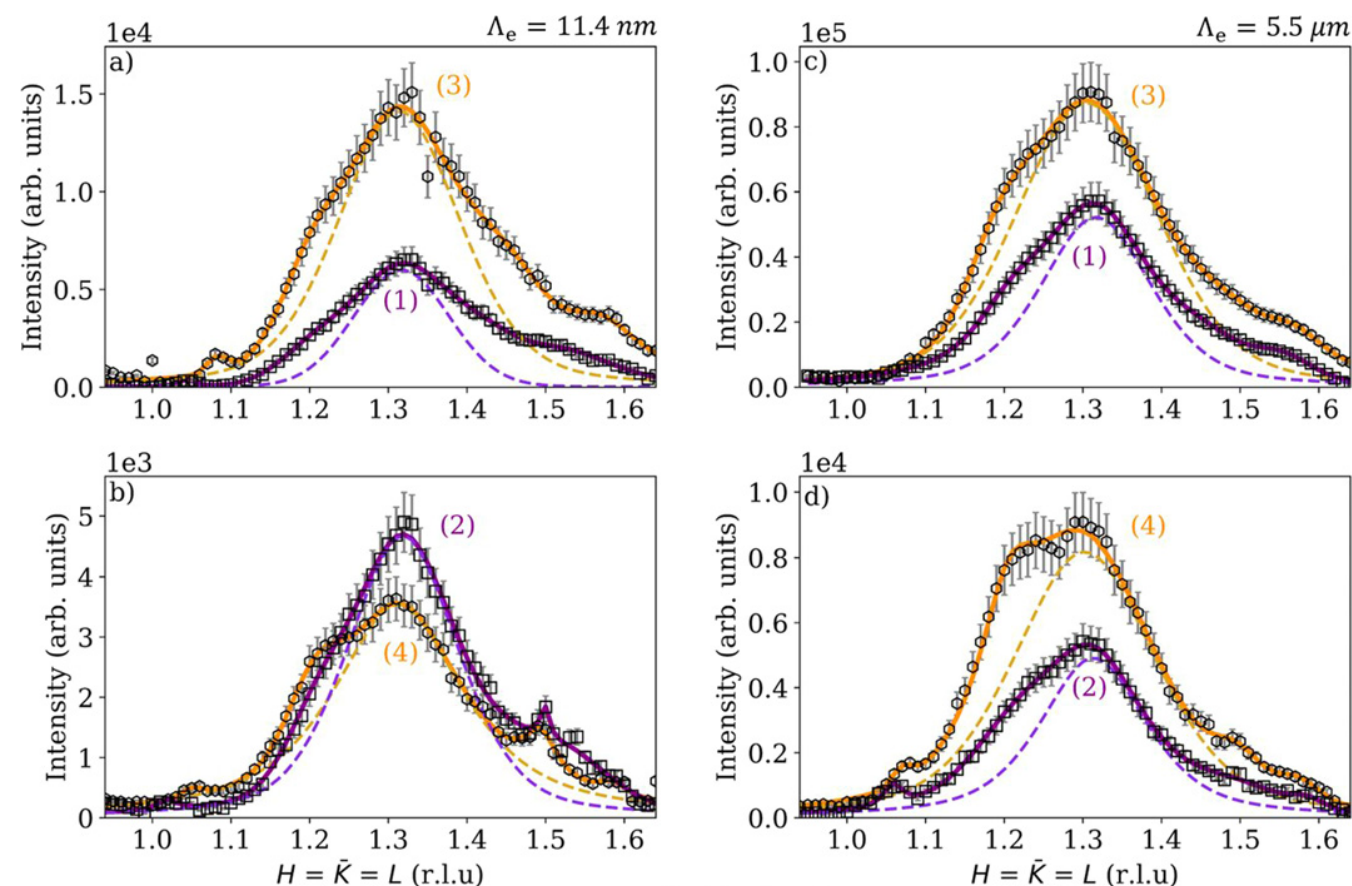

e)
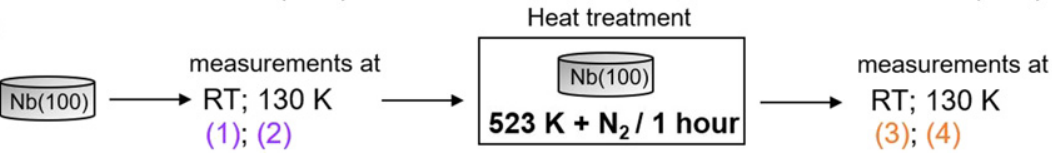

Figure 4. Diffuse intensity along the [1111] $\mathrm{Nb}$ direction recorded at room temperature (a) and (c) and $130 \mathrm{~K}$ (b) and (d) for the $\mathrm{Nb}(100)$ sample at two effective scattering depths $\Lambda_{\mathrm{e}}$ of $11.4 \mathrm{~nm}$ (left) and $5.5 \mu \mathrm{m}$ (right). Scans obtained before the thermal treatment are represented by black squares, while its corresponding best fits are shown as solid purple lines. Measurements after the annealing are shown as black hexagons with the corresponding best fits presented as solid orange lines. Dashed lines depict the components associated with the interstitial diffuse scattering together with the TDS contribution. The remaining contributions are omitted for better visualization. A timeline of the measurements is shown in (e). First, the sample was measured at two different temperatures (room temperature and $130 \mathrm{~K}$ ) followed by the thermal treatment performed at $523 \mathrm{~K}$ under $\mathrm{N}_{2}$ atmosphere for $1 \mathrm{~h}$. The sample was remeasured at the same temperatures after the heat treatment.

correlated with the behavior of the subsurface oxygen interstitial atoms under such conditions. This is presented in the next section.

\subsection{X-ray diffuse scattering from interstitials}

The bcc lattice of $\mathrm{Nb}$ possesses an intrinsic instability along the [111] direction, manifested by a soft phonon mode at $\mathbf{k}=$ $\frac{2}{3}(1,1,1)[49]$. Local distortions caused by interstitial atoms in the octahedral sites of the lattice can act as nucleation sites for the so-called omega phase of $\mathrm{Nb}$ and are strongly coupled to this instability, breaking the original lattice symmetry [50]. Fingerprints of such distortions are diffuse maxima centered at the reduced scattering vector $\mathbf{Q}^{*}=\frac{2}{3}(1,1,1)$ and space group I $m-3 m$ symmetry equivalents in reciprocal space [41, 50-53]. This diffuse intensity, in a low defect concentration regime, is proportional to $c(1-c)$, where $c$ is the defect concentration $[41,50]$. Therefore, by monitoring such intensities at different probed depths, it is possible to retrieve valuable information about the presence or absence of interstitial atoms in the subsurface region of $\mathrm{Nb}[40,41]$.

Figure 4 shows the measured line scans in the [111] $\mathrm{Nb}$ direction crossing the expected diffuse intensity at $\mathbf{Q}=\frac{4}{3}[1 \overline{1} 1]$ at room temperature (a) and (c) and $130 \mathrm{~K}$ (b) and (d) before and after annealing at $523 \mathrm{~K}$ in a nitrogen atmosphere at a constant pressure of $3.3 \times 10^{-2}$ mbar for $1 \mathrm{~h}$. The incident angle of $\mathrm{x}$-rays was maintained fixed at two different values, $0.04^{\circ}$ and $0.4^{\circ}$, corresponding to the effective scattering depths $\Lambda_{\mathrm{e}}$ of $11.4 \mathrm{~nm}$ and $5.5 \mu \mathrm{m}$ [54]. The expected interstitial and thermal diffuse scattering (TDS) fingerprints are observed at $H=\bar{K}=L=1.30$ reciprocal lattice units (r.l.u). The remaining contributions are due to the presence of $\mathrm{NbO}_{2}$, in line with what is reported for the $\mathrm{Nb}(110)$ surface [41], and by the beryllium $(\mathrm{Be})$ windows of the experimental chamber. As the specimen is cooled down to $130 \mathrm{~K}$, the overall intensity of the signal lowers, especially the TDS contribution. In turn, the Be (102) reflection emerges. The corresponding assignment of the different pseudo-Voigt components necessary to fully reproduce the observed curves is depicted in appendix $\mathrm{C}$.

At room temperature (figures 4(a) and (c)), the overall intensity of the diffuse signal increased after the thermal treatment ( $523 \mathrm{~K}$ in $\mathrm{N}_{2}$ atmosphere) when compared to the sample state before it, indicating that the oxygen liberated from the consumption of the natural oxide layers diffused into the $\mathrm{Nb}$ matrix and populated the areas in the close vicinity of the oxide/metal interface. Similar results were reported for single-crystalline $\mathrm{Nb}(110)$ and (100) oriented specimens, for which an oxygen enrichment in the first tens of nanometers was observed during annealing at temperatures between 
a)

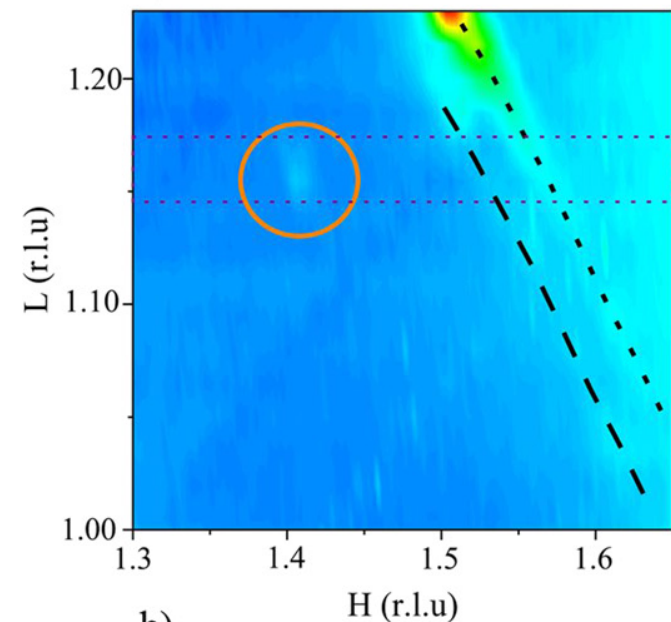

b)

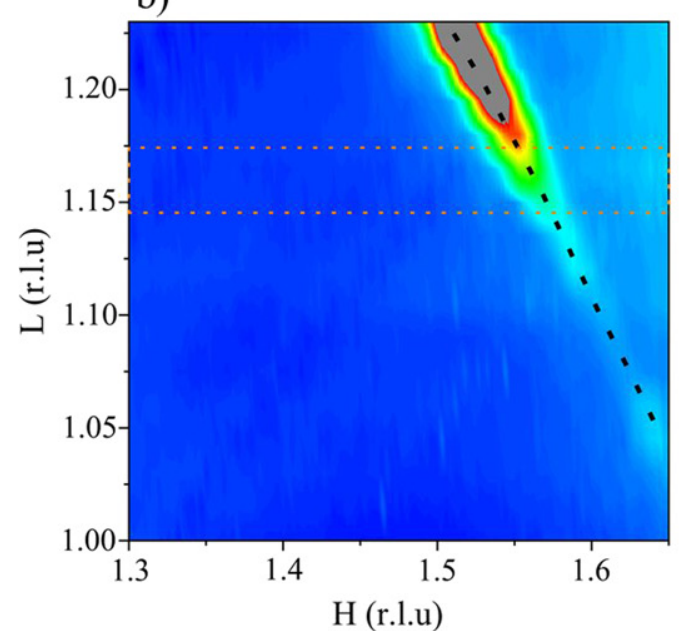

c)

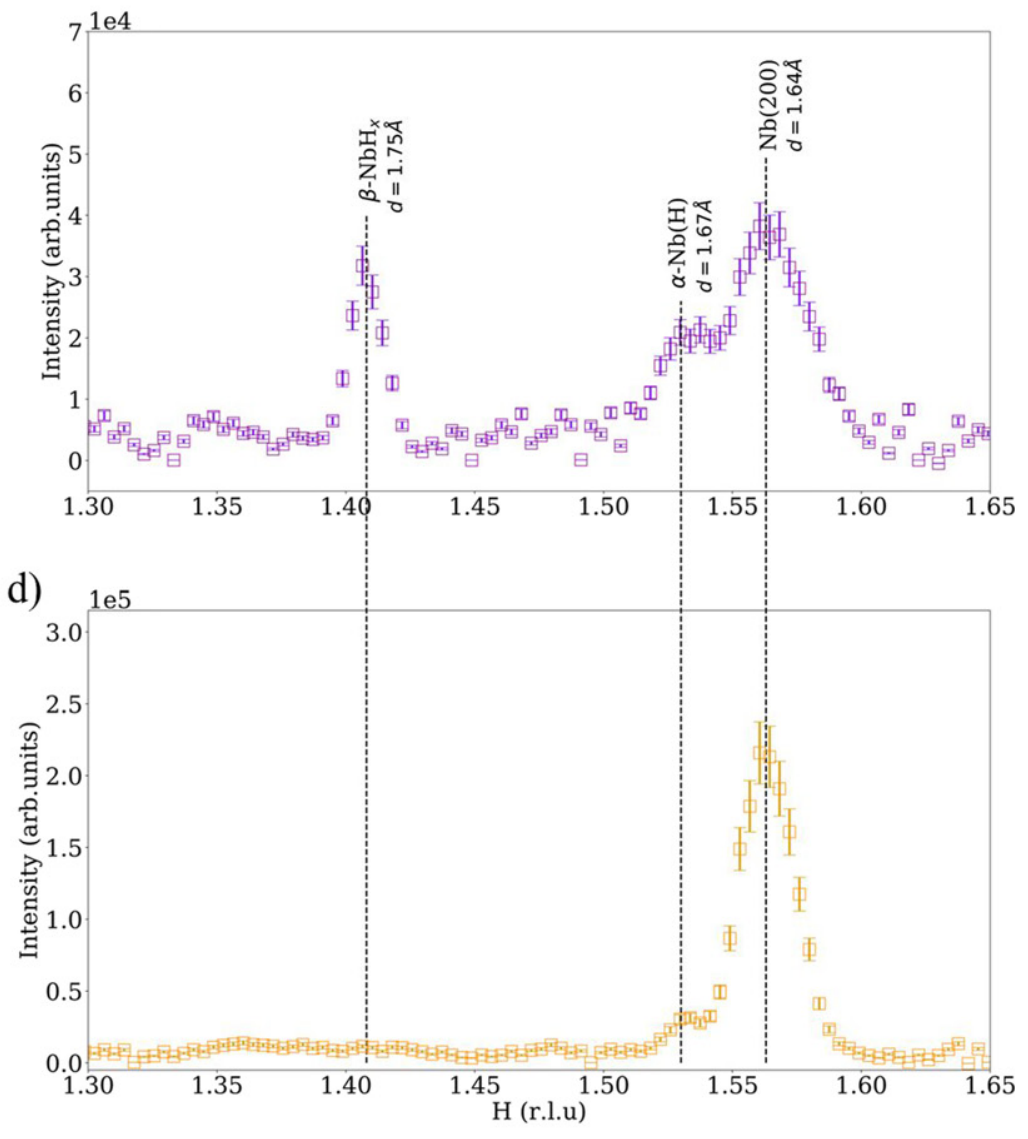

Figure 5. Reciprocal space maps obtained at a fixed incident angle of $0.5^{\circ}$, corresponding to a scattering depth of $\approx 7.4 \mu \mathrm{m}$, for the hydrogen loaded $\mathrm{Nb}(100)$ at $130 \mathrm{~K}$ and their respective intensities extracted from the maps, between the horizontal dotted lines, in the reciprocal H-direction centered at a fixed $L=1.17$ r.l.u before (a) and (c) and after (b) and (d) the nitrogen annealing. The dashed lines highlight powder rings of different $\mathrm{Nb}$ grains present in the sample while the orange circle highlights the position of a possible $\beta-\mathrm{NbH}_{x}$ reflection. The maps are shown with the same intensity scale while the plots in (c) and (d) were corrected with a slope background.

$390 \mathrm{~K}$ and $420 \mathrm{~K}[40,41]$. In agreement with the XRR results, $\mathrm{NbO}_{2}$ remained at the surface after the thermal treatment, as its corresponding reflections are still observed. Furthermore, the increased signal of these contributions suggest that a better ordering of $\mathrm{NbO}_{2}$ was achieved after the annealing. The increase in the measured diffuse intensity after the thermal treatment is credited mostly to the presence of oxygen interstitials in the near-surface region. The oxygen concentration can be estimated from the natural oxide consumption retrieved by XRR and amounts for $\approx 14$ at.\% within the first $10 \mathrm{~nm}$ of the $\mathrm{Nb}$ specimen. Based on previous works, the presence of interstitial nitrogen atoms in $\mathrm{Nb}$ with a concentration above $\approx 1$ at. $\%$ can be disregarded under the conditions explored here $[40,55]$. However, it is still possible that nitrogen has diffused into the near-surface region of $\mathrm{Nb}$ below this limit, contributing to the detected diffuse intensity. Moreover, the diffusion length of nitrogen in $\mathrm{Nb}$ for the present conditions is expected to be limited to $\approx 3 \mathrm{~nm}$ [21], such that contributions from interstitial nitrogen in the measured signal are only reasonable for small probed depths as presented in figures 4(a) and (b).

Interestingly, upon cooling the $\mathrm{Nb}$ specimen to $130 \mathrm{~K}$, the diffuse signal obtained after the aforementioned thermal treatment (523 K in $\mathrm{N}_{2}$ atmosphere) is lower than before it when considering a scattering depth of $11.4 \mathrm{~nm}$ from the surface to the bulk (orange and purple curves in figure 4(b), respectively). This observation can be explained by potential temperature-induced segregation of interstitial species. The thermal treatment at $523 \mathrm{~K}$ in nitrogen atmosphere, which completely consumes $\mathrm{Nb}_{2} \mathrm{O}_{5}$ and also partially $\mathrm{NbO}_{2}$ and $\mathrm{NbO}$, liberates oxygen atoms that can diffuse towards the $\mathrm{Nb}$ bulk, therefore increasing the diffuse intensity near the surface as well as in the bulk (orange curves in figures 4(a) and (c)). For the conditions discussed here, the diffusion length of oxygen in $\mathrm{Nb}$ is estimated to be around $250 \mathrm{~nm}$ [21], agreeing with the observed interstitial-induced diffuse signal increase for both probed depths (11.4 nm and $5.5 \mu \mathrm{m})$. Furthermore, nitrogen's potential presence adds up to the measured signal close to the 

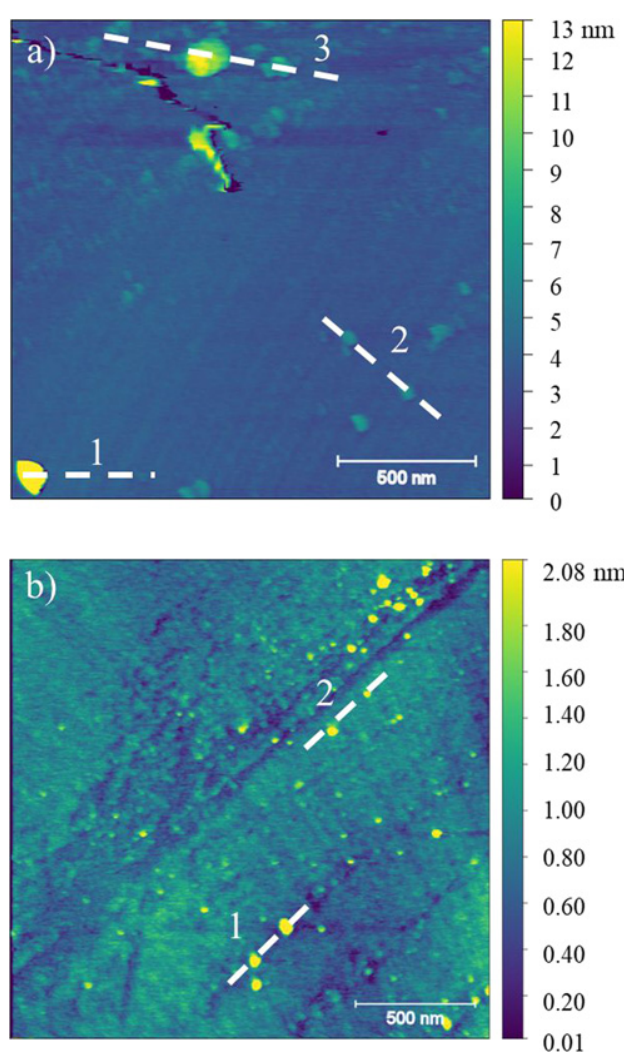

c)

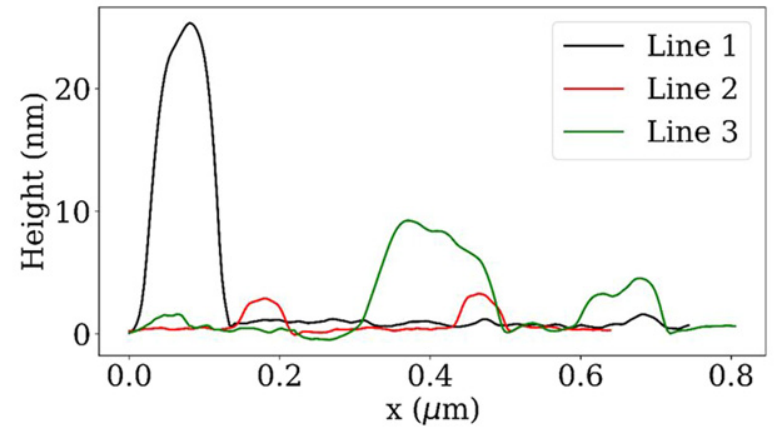

d)

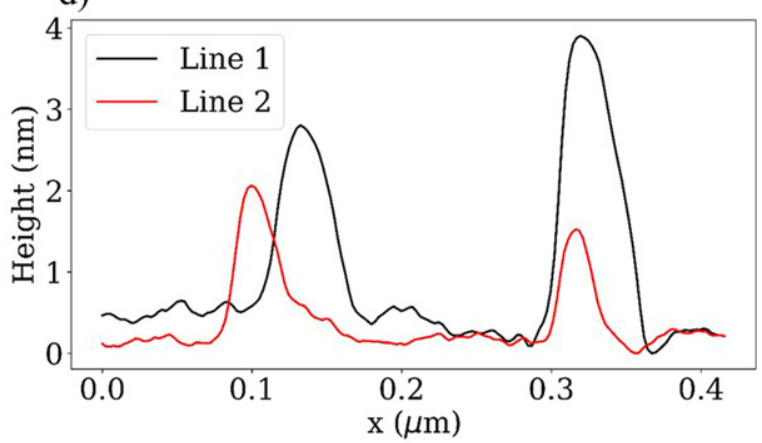

Figure 6. AFM images of the hydrogen loaded $\mathrm{Nb}(100)$ sample under liquid nitrogen cooling (a) and the corresponding line profiles extracted from the images, indicated by the dashed white lines (c). The smaller precipitates still remained visible at $275 \mathrm{~K}$ (b). The corresponding line profiles are shown in (d).

surface. As the temperature is lowered to $130 \mathrm{~K}$, the interstitial atoms in close vicinity of the oxide/metal interface segregate towards the surface, decreasing the measured diffuse intensity in that region (orange curve in figure 4(b)). Such segregation is only observed close to the oxide/metal interface since, for larger probed depths (figure 4(d)), the measured diffuse intensity after the discussed thermal treatment is higher than prior to it (purple and orange curves in figure 4(d)).

\subsection{Niobium hydride formation at low temperatures}

3.4.1. In situ grazing-incidence x-ray diffraction. A comparison between GIXRD reciprocal space maps and their respective extracted intensities in the reciprocal H-direction, before (a) and (c) and after (b) and (d) the nitrogen thermal treatment, are shown in figure 5. The maps were collected at the plane $K=\frac{1}{2}$ r.l.u of $\mathrm{Nb}$, where Bragg reflections belonging to $\beta-\mathrm{NbH}$ are expected to appear $[14,56-58]$. The measurements were performed at $130 \mathrm{~K}$ with a fixed incident angle $\mu=0.5^{\circ}$, corresponding to a scattering depth $\Lambda_{\mathrm{e}}=7.4 \mu \mathrm{m}$. Initially, three different signals can be observed (figures 5(a) and (c)). Two powder ring intensities, corresponding to d-spacings of $1.64 \AA$ (dotted line) and $1.67 \AA$ (dashed line), and an extra reflection corresponding to a d-spacing of $1.75 \AA$ (orange circle). The powder ring signals are compatible with (002)-type reflections of $\mathrm{Nb}$ and $\alpha-\mathrm{Nb}(\mathrm{H})$, the latter associated with the weaker signal with a d-spacing of $1.67 \AA$, indicating an expansion of the parent $\mathrm{Nb}$ bcc lattice due to hydrogen incorporation. The presence of these powder-like intensities reveals the existence of small and rotated $\mathrm{Nb}$ grains within the otherwise single-crystalline sample. The additional peak, highlighted by an orange circle in figure 5(a) and correspondingly observed in the line profile in figure 5(c) centered around $H=1.41$ r.l.u, is compatible with at least two different $\beta-\mathrm{NbH}_{x}$ reflections, namely (200) and (220), for the orthorhombic crystal structure of $\beta-\mathrm{NbH}_{x}$ [57]. A Vegard's law approximation using the lattice parameters of $\beta-\mathrm{NbH}$ and pure $\mathrm{Nb}$ yields a hydrogen content of $\approx 4$ at. $\%$ for the $\alpha-\mathrm{Nb}(\mathrm{H})$ solid solution, in good agreement with the estimated $c_{\text {hydrogen }}$ of $1.0 \pm 0.5$ at. $\%$.

After annealing, only the powder signals corresponding to the (002)-type reflections of $\mathrm{Nb}$ and $\alpha-\mathrm{Nb}(\mathrm{H})$ were observed (dotted line in figure 5(b) and peaks in figure 5(d)), a strong indication that the extra intensity recorded before the treatment originated from the $\beta-\mathrm{NbH}_{x}$ phase, which was consumed by the annealing. The fact that the intensity contribution from $\alpha-\mathrm{Nb}(\mathrm{H})$ remained in a similar range before and after the thermal treatment suggests that the annealing temperature or its duration is not enough to completely release hydrogen from niobium, although being capable of drastically lowering its concentration.

3.4.2. Atomic force microscopy. In order to correlate the results obtained by in situ GIXRD, AFM measurements were performed on a similar hydrogen-loaded $\mathrm{Nb}(100)$ specimen. The AFM image processing, namely the leveling correction 

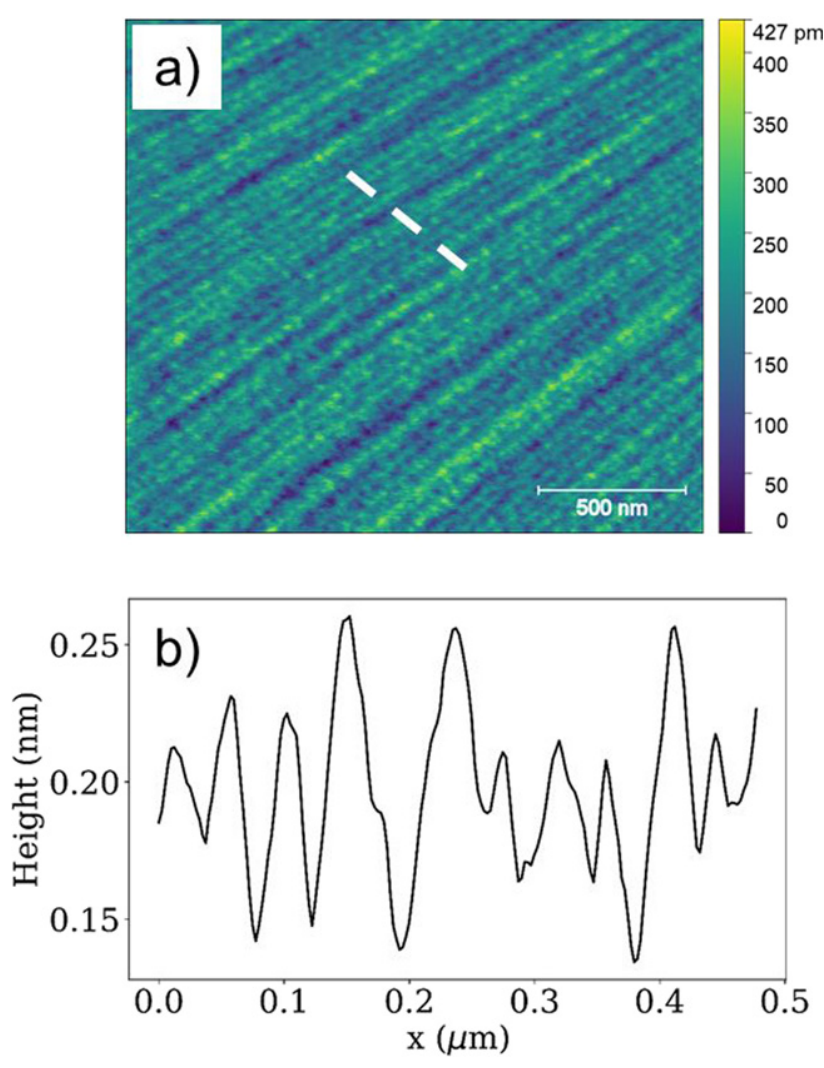

Figure 7. Hydrogen loaded $\mathrm{Nb}(100)$ observed by $\mathrm{AFM}$ at room temperature after annealing at $400 \mathrm{~K}$ for $2 \mathrm{~h}$ (a). Line profile corresponding to the dashed line region (b). No precipitates were observed after the UHV annealing.

and extraction of line profiles, was performed with Gwyddion [59]. Initially, at room temperature, only large terraces with an average length of $\approx 60 \mathrm{~nm}$ can be observed (see figure 9 in appendix D). No precipitates were detected, indicating that the initial hydrogen concentration was too low to induce $\mathrm{NbH}_{x}$ species' precipitation at room temperature in agreement with the $\mathrm{Nb}-\mathrm{H}$ phase diagram [60].

The specimen was then cooled down from room temperature to $108 \mathrm{~K}$ in $\approx 2 \mathrm{~h}$, while the pressure in the UHV chamber was kept in the $10^{-10}$ mbar range. As presented in figure 6(a), precipitates with two height distributions were observed at such temperature-larger ones, with heights between $\approx 10$ and $\approx 25 \mathrm{~nm}$, and smaller ones with $\approx 3 \mathrm{~nm}$ in height. The corresponding line profiles are shown in figure 6(c). The sample was warmed up to $275 \mathrm{~K}$ to verify the thermal stability of the formed precipitates. One of the acquired images at this stage, together with its respective line profile, is shown in figures 6(b) and (d). A large number of small precipitates of about $\approx 3 \mathrm{~nm}$ in height can be observed, especially close to surface imperfections. Figure 7 shows the sample's surface at room temperature, after annealing at $400 \mathrm{~K}$ for $2 \mathrm{~h}$ in UHV. At this stage, only terraces with an average length of $\approx 50 \mathrm{~nm}$ were observed. As expected due to the low hydrogen concentration in the $\mathrm{Nb}$ specimen, no indication of precipitates was detected.

\section{Discussion}

As shown here, the distribution of interstitial atoms close to the oxide/metal interface of $\mathrm{Nb}$ is altered upon cooldown to $130 \mathrm{~K}$, together with the thickness and electron density of the natural surface oxide layers of $\mathrm{Nb}$. Such finding is especially relevant for $\mathrm{SRF}$ applications of $\mathrm{Nb}$, since its transition temperature $T_{\mathrm{c}}$ to the superconducting state was shown to be severely affected by the oxygen concentration $\mathrm{c}_{\text {oxygen }}$ in the $\mathrm{Nb}$ matrix, with its value decreasing to $5.84 \mathrm{~K}$ when $c_{\text {oxygen }}=3.83$ at. $\%$ and reaching $9.02 \mathrm{~K}$ when $c_{\text {oxygen }}=6.43$ at. $\%$ [2]. Moreover, the presence of impurities in the RF penetration depth $(\approx 50-100 \mathrm{~nm}$ for $\mathrm{Nb}$ ) affects the electronic mean free path and energy gap of $\mathrm{Nb}$ SRF cavities, leading to an enhanced performance of such devices [25, 61]. Similar segregation effects, as observed here, were previously reported in the literature for $\mathrm{Nb}$, but for higher temperatures. Interstitial oxygen was observed to segregate towards the surface of $\mathrm{Nb}$ above $773 \mathrm{~K}$, reaching a maximum while at $1573 \mathrm{~K}$. At even higher temperatures, oxygen is removed from the $\mathrm{Nb}$ specimens, mainly by the evaporation of lower $\mathrm{Nb}$ oxides [21, 62]. After cooling from temperatures above $773 \mathrm{~K}$ down to room temperature, pronounced oxygen segregation towards the surface was reported [62]. A similar process is observed here, however, now at cryogenic temperatures, which highlights the need for a complete characterization of the near-surface region of $\mathrm{Nb}$ not only during and after similar thermal treatments applied to real cavities but also simulating its operating conditions. For instance, it has been reported that hydrogen tends to segregate to the surface of $\mathrm{Nb}$ [9], thus coinciding with the segregation of interstitial species observed here. A potential scenario is that when at low temperatures, the available oxygen and possible nitrogen atoms segregate towards the surface where an excessive hydrogen concentration is present. This effect can lead to the trapping of hydrogen atoms, eventually suppressing the formation of performance-degrading niobium hydrides $[15,19,23,24,63]$.

The low-temperature segregation presented here has not only potential severe implications to SRF-based accelerator research but also for 3D-QED architectures in quantum computing. The presence of impurities such as nitrogen and oxygen in the near-surface region of $\mathrm{Nb}$ cavities, allied with the natural oxide layer of $\mathrm{Nb}$, were reported to act as possible coherence degrading agents [30]. Therefore, further studies aiming to understand the effects of extremely low temperatures, such as below $10 \mathrm{~K}$, in the concentration and distribution of subsurface interstitials in $\mathrm{Nb}$ surge as a necessity in order to evaluate the possible sources of coherence losses and effectively control them.

The formation of niobium hydrides at cryogenic temperatures after the mild-temperature $\mathrm{H}_{2}$ loading performed in this work contradicts reports that hydrogen can only effectively enter $\mathrm{Nb}$ if the natural layer of $\mathrm{Nb}_{2} \mathrm{O}_{5}$ is not present, even though it is well-established that at room temperature, hydrogen incorporation, as well as its evolution, is hindered [16]. Similar niobium hydride precipitates as observed here were 
reported in studies involving SRF cavity-grade $\mathrm{Nb}$ material, where the samples in question had hydrogen concentrations between 0.22 and 0.66 at.\% [8]. The presence of $\beta-\mathrm{NbH}$ was also observed by TEM measurements performed at $94 \mathrm{~K}$ in cavity cut-outs, which underwent a typical EP procedure [14]. For both cases, similar to the results presented here, annealing at mild temperatures was reported to lead to a drastic decrease (or complete disappearance) in the amount of niobium hydride structures at the surface of Nb. Such observation is also consistent with the proximity breakdown model proposed in [15]. Also in agreement with the findings presented here are the reports that the dissociation of vacancy-hydrogen complexes occur in a temperature range of $350-400 \mathrm{~K}$, and thus mitigating the formation of niobium hydrides [64]. Furthermore, STM and STS studies also showed the suppression of niobium hydride formation on nitrogen and hydrogen co-doped $\mathrm{Nb}(100)$ surfaces [65]. Not only hydrogen is highly mobile in the $\mathrm{Nb}$ matrix at the annealing conditions studied here [21], allowing it to be expelled from the sample and therefore lowering its associated hydrogen concentration but also the trapping of hydrogen atoms by vacancies, oxygen, and nitrogen may occur, even though that the nitrogen concentration is assumed to be below $\approx 1$ at. $\%$ if any. As evidenced by the $\mathrm{x}$-ray diffuse scattering measurements, the subsurface interstitial concentration dramatically increases after the thermal treatment (523 K in nitrogen atmosphere), in line with the complete consumption of $\mathrm{Nb}_{2} \mathrm{O}_{5}$ observed by XRR. At this stage, it is possible that a situation where $c_{\text {oxygen }}+c_{\text {nitrogen }}>c_{\text {hydrogen }}$ is achieved, therefore disrupting the niobium hydrides and increasing the diffusion barrier of hydrogen as well as favoring its trapping, which avoids clustering and the eventual reprecipitation of the hydride phase [15, 19, 23, 24, 63-65].

\section{Conclusions}

The effect of cryogenic temperatures on the native oxides of $\mathrm{Nb}$, subsurface interstitial atoms, and formation of niobium hydrides was studied in the near-surface region of singlecrystalline $\mathrm{Nb}(100)$. Hydrogen was successfully incorporated into the $\mathrm{Nb}$ matrix by prolonged annealing in $\mathrm{H}_{2}$ atmosphere and resulted in a concentration of about 1 at.\%. In situ GIXRD and complementary AFM measurements evidenced the presence of niobium hydrides on the $\mathrm{Nb}(100)$ specimens upon cooldown to $130 \mathrm{~K}$ and $108 \mathrm{~K}$. The formation of hydrides was entirely suppressed by annealing at $523 \mathrm{~K}$ in $\mathrm{N}_{2}$ atmosphere for $1 \mathrm{~h}$. Such an annealing step can potentially be introduced into the preparation steps of typical cavity treatments to reduce the current total time and cost of the complete process.

Depth-resolved x-ray diffuse scattering measurements indicated the segregation of subsurface interstitial oxygen and potentially nitrogen atoms towards the $\mathrm{Nb}$ surface upon cooldown to $130 \mathrm{~K}$. This process alters the distribution of such interstitials within the RF penetration depth of $\mathrm{Nb}$. In the case of oxygen segregation, it can lead to a slight growth of the natural oxide layer, as concluded from the XRR results.

These findings indicate that the distribution of interstitial atoms in the near-surface region of $\mathrm{Nb}$, pivotal for the performance of Nb SRF cavities, can drastically change upon cooling
Table 1. Sample conditions during the hydrogen loading.

\begin{tabular}{lcc}
\hline Temperature & $\mathrm{H}_{2}$ pressure & Annealing time (hh:min) \\
\hline $393 \mathrm{~K}$ & $1 \times 10^{-6} \mathrm{mbar}$ & $23: 15$ \\
& $1 \times 10^{-5} \mathrm{mbar}$ & $12: 20$ \\
& $1 \times 10^{-4} \mathrm{mbar}$ & $10: 15$ \\
$423 \mathrm{~K}$ & $1 \times 10^{-4} \mathrm{mbar}$ & $09: 20$ \\
\hline
\end{tabular}

Table 2. Thickness (roughness) in nm obtained with the Parrat formalism before and after annealing while at room temperature (RT) and at $130 \mathrm{~K}$. A slight increase in the total thickness of the natural oxides is systematically observed (error bar of $\pm 0.1 \mathrm{~nm}$ ).

\begin{tabular}{lccccc}
\hline & \multicolumn{2}{c}{ Initial } & & \multicolumn{2}{c}{$523 \mathrm{~K}+\mathrm{N}_{2}$} \\
\cline { 2 - 3 } \cline { 5 - 6 } Phase & $\mathrm{RT}$ & $130 \mathrm{~K}$ & & $\mathrm{RT}$ & $130 \mathrm{~K}$ \\
\hline $\mathrm{Nb}_{2} \mathrm{O}_{5}$ & $1.2(0.3)$ & $1.3(0.3)$ & & - & - \\
$\mathrm{NbO}_{2}$ & $0.9(0.2)$ & $0.8(0.2)$ & & $0.5(0.2)$ & $0.5(0.2)$ \\
$\mathrm{NbO}$ & $0.6(0.2)$ & $0.8(0.3)$ & & $0.6(0.2)$ & $0.6(0.2)$ \\
$\mathrm{Nb}$ & $(0.1)$ & $(0.1)$ & & $(0.3)$ & $(0.3)$ \\
Total & 2.7 & 2.9 & & 1.1 & 1.1 \\
\hline
\end{tabular}

Table 3. Electron densities in $\AA^{-3}$ retrieved from the XRR measurements while at room temperature (RT) and at $130 \mathrm{~K}$, before and after annealing. An error bar of $\pm 0.01 \AA^{-3}$ was estimated.

\begin{tabular}{lllllr}
\hline & \multicolumn{2}{c}{ Initial } & & \multicolumn{2}{c}{$523 \mathrm{~K}+\mathrm{N}_{2}$} \\
\cline { 2 - 3 } \cline { 5 - 6 } Phase & $\mathrm{RT}$ & $130 \mathrm{~K}$ & & $\mathrm{RT}$ & $130 \mathrm{~K}$ \\
\hline $\mathrm{Nb}_{2} \mathrm{O}_{5}$ & 1.22 & 1.11 & & - & - \\
$\mathrm{NbO}_{2}$ & 1.50 & 1.42 & & 1.43 & 1.41 \\
$\mathrm{NbO}$ & 2.10 & 2.14 & & 1.67 & 1.68 \\
\hline
\end{tabular}

to cryogenic temperatures. Such effects are so far unaccounted for when dealing with thermal treatments applied to SRF Nb cavities as well as its consequences to the performance of such devices. Further combinatorial studies employing polycrystalline $\mathrm{Nb}$ specimens, for example, exploring operating temperatures of SRF cavities focusing on the near-surface region of $\mathrm{Nb}$ would immensely aggregate to the current understanding of such devices. This could impact not only the conception of new particle accelerators but also the field of quantum computing, where the distribution of interstitial species and the natural oxide layer of $\mathrm{Nb}$ play an important role in extending the coherence times in SRF-based quantum circuits.

\section{Acknowledgments}

The authors thank T Meisner and A Weible for the UHVinduction annealing of the $\mathrm{Nb}$ crystals at MPI for Intelligent Systems and the ESRF for the allocated beamtime under proposal number HC-3513. The preparation of the UHV chamber and sample environment before the experiment allied with the support during the beamtime at ID03 by H Isern, L Pythan, P Bayer, and M Sandroni is acknowledged. Author G D L S acknowledges the funding from the BMBF project OPSCURES, Grant No. 05H18GURB1. 


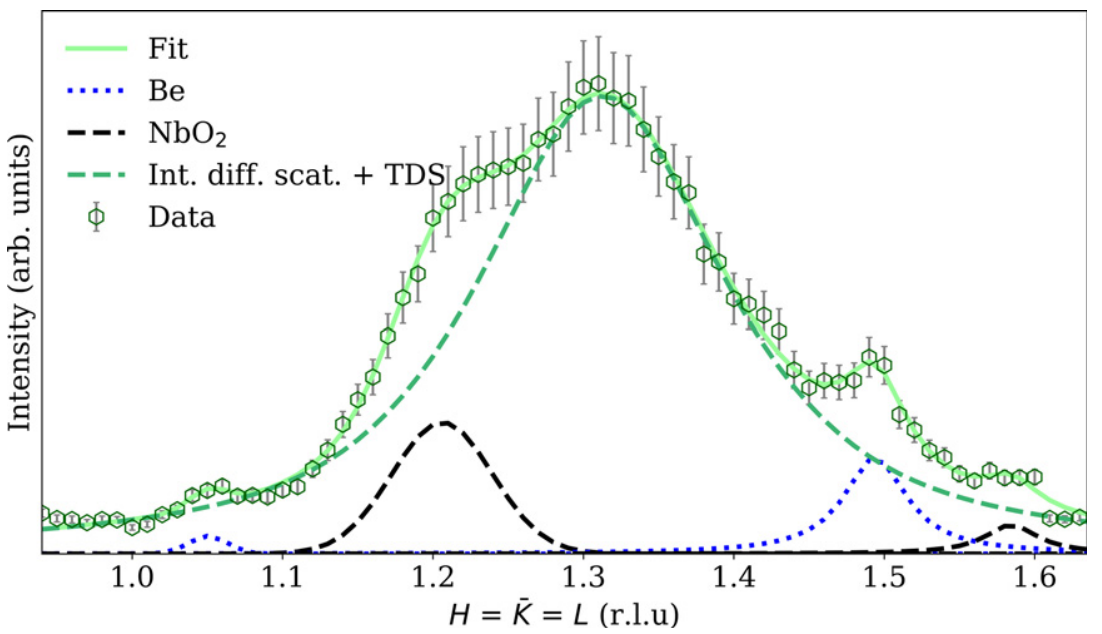

Figure 8. Example of a line scan in the [1 $1 \overline{1} 1] \mathrm{Nb}$ direction recorded at $130 \mathrm{~K}$ for the hydrogen loaded $\mathrm{Nb}(100)$ sample after annealing at $523 \mathrm{~K}$ in $\mathrm{N}_{2}$ atmosphere at a scattering depth $\Lambda_{\mathrm{e}}$ of $11.4 \mathrm{~nm}$. The different pseudo-Voigt components that make up the complete line profile are individually depicted.

a)

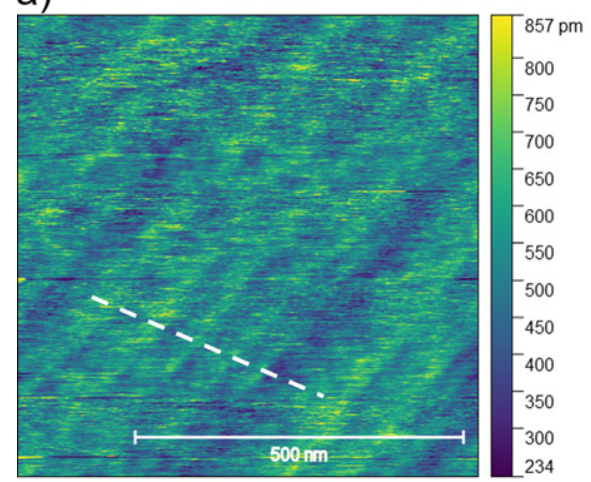

b)

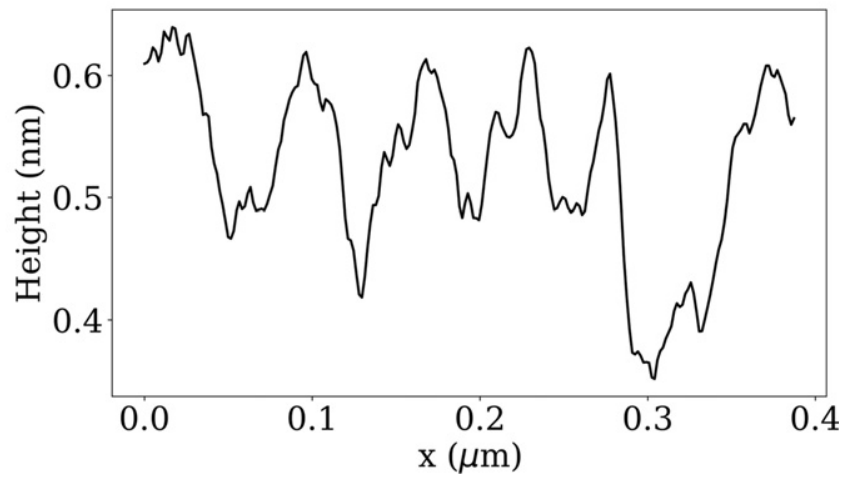

Figure 9. AFM image (a) obtained for a hydrogen-loaded $\mathrm{Nb}(100)$ sample at room temperature. The line profile (b) was extracted from the dashed region, perpendicular to the terraces which display an average length of $\sim 60 \mathrm{~nm}$. No precipitates were detected.

\section{Data availability statement}

All data that support the findings of this study are included within the article (and any supplementary files).

\section{Appendix A. Hydrogen loading}

The following table lists the details, such as hydrogen pressure, temperature and annealing times for the hydrogen loading procedures (table 1).

\section{Appendix B. X-ray reflectivity fit results}

The following tables list the fit results of the XRR measurements taken at different temperatures and gas environments.

\section{Appendix C. X-ray diffuse scattering pseudo-Voigt components}

The following figure shows the different diffraction peak components of the intensity along the [1 $1 \overline{1} 1] \mathrm{Nb}$ direction (figure 8).

\section{Appendix D. Room temperature AFM}

The following figure shows a typical AFM topography image and height profile of $\mathrm{Nb}(001)$ take at room temperature.

\section{ORCID iDs}

Guilherme Dalla Lana Semione (1) https://orcid.org/00000003-2210-337X

Vedran Vonk (ㄴ) https://orcid.org/0000-0001-9854-1101

Elin Grånäs (1) https://orcid.org/0000-0001-5247-7589

Marc Wenskat (1) https://orcid.org/0000-0001-6546-770X

Heshmat Noei (1) https://orcid.org/0000-0003-1294-3527

Andreas Stierle (1) https://orcid.org/0000-0002-0303-6282

\section{References}

[1] Padamsee H, Knobloch J and Hays T 2008 RF Superconductivity for Accelerators (New York: Wiley-VCH) 
[2] DeSorbo W 1963 Phys. Rev. 132107

[3] Antoine C 2019 Phys. Rev. Accel. Beams 22034801

[4] Garg P, Muhich C, Cooley L D, Bieler T R and Solanki K N 2020 Phys. Rev. B 101184102

[5] Dhakal P, Ciovati G and Gurevich A 2020 Phys. Rev. Accel. Beams 23023102

[6] Tsvilyuk I S, Pyl'nikov V A and Men'shikh V A 1976 Strength Mater. 81421

[7] Hardie D and McIntyre P 1973 Metall. Trans. 41247

[8] Barkov F, Romanenko A and Grassellino A 2012 Phys. Rev. Spec. Top. Accel. Beams 15122001

[9] Antoine C Z 2003 AIP Conf. Proc. vol 671 (New York: AIP Publishing) 176-89

[10] Singer W et al 2016 Phys. Rev. Accel. Beams 19092001

[11] Reschke D, Gubarev V, Schaffran J, Steder L, Walker N, Wenskat M and Monaco L 2017 Phys. Rev. Accel. Beams 20 042004

[12] Grassellino A et al 2013 Supercond. Sci. Technol. 26102001

[13] Grassellino A et al 2017 Supercond. Sci. Technol. 30094004

[14] Trenikhina Y, Romanenko A, Kwon J, Zuo J-M and Zasadzinski J F 2015 J. Appl. Phys. 117154507

[15] Romanenko A, Barkov F, Cooley L D and Grassellino A 2013 Supercond. Sci. Technol. 26035003

[16] Ricker R and Myneni G 2010 J. Res. Natl Inst. Stand. Technol. 115353

[17] Ciovati G, Myneni G, Stevie F, Maheshwari P and Griffis D 2010 Phys. Rev. Spec. Top. Accel. Beams 13022002

[18] Knobloch J 2003 AIP Conf. Proc. vol 671 (New York: AIP) $133-50$

[19] Metzger T H, Schubert U and Peisl J 1985 J. Phys. F: Met. Phys. 15779

[20] Pick M A and Bausch R 1976 J. Phys. F: Met. Phys. 61751

[21] Fromm E and Gebhardt E 1976 Gase und Kohlenstoff in Metallen (Berlin: Springer)

[22] Rauch G C, Rose R M and Wulff J 1965 J. Less Common Met. 899

[23] Ford D C, Cooley L D and Seidman D N 2013 Supercond. Sci. Technol. 26105003

[24] Pfeiffer G and Wipf H 1976 J. Phys. F: Met. Phys. 6167

[25] Martinello M, Grassellino A, Checchin M, Romanenko A, Melnychuk O, Sergatskov D A, Posen S and Zasadzinski J F 2016 Appl. Phys. Lett. 109062601

[26] Lechner E M, Oli B D, Makita J, Ciovati G, Gurevich A and Iavarone M 2020 Phys. Rev. Appl. 13044044

[27] Isagawa S 1980 J. Appl. Phys. 514460

[28] Myzenkova L F, Baron V V and Savitskii E M 1970 Physics and Metallurgy of Superconductors (Berlin: Springer) pp 3-9

[29] DeSorbo W 1964 Phys. Rev. 134 A1119

[30] Romanenko A, Pilipenko R, Zorzetti S, Frolov D, Awida M, Belomestnykh S, Posen S and Grassellino A 2018 Phys. Rev. Appl. 13034032

[31] Paik H et al 2011 Phys. Rev. Lett. 107240501

[32] Kutsaev S, Taletski K, Agustsson R, Carriere P, Cleland A, Conway Z, Dumur E, Moro A and Smirnov A 2020 EPJ Quantum Technol. 77

[33] Romanenko A, Pilipenko R, Zorzetti S, Frolov D, Awida M, Belomestnykh S, Posen S and Grassellino A 2020 Phys. Rev. Appl. 13034032
[34] Kusunoki M, Yamamori H, Fujimaki A, Takai Y and Hayakawa H 1993 Japan J. Appl. Phys. 32 L1609

[35] Dove A 2014 Sources of noise in niobium-based superconducting quantum circuits Dissertation University of Illinois at Urbana-Champaign

[36] Parratt L G 1954 Phys. Rev. 95359

[37] Tolan M 1999 X-Ray Scattering from Soft-Matter Thin Films (Berlin: Springer)

[38] Stierle A FEWLAY: a software for fitting x-ray reflectivity curves andreas.stierle@desy.de.

[39] Ford D C, Cooley L D and Seidman D N 2013 Supercond. Sci. Technol. 26095002

[40] Semione G et al 2019 Phys. Rev. Accel. Beams 22103102

[41] Delheusy M et al 2008 Appl. Phys. Lett. 92101911

[42] Rieder K H 1980 Appl. Surf. Sci. 4183

[43] Lindau I and Spicer W E 1974 J. Appl. Phys. 453720

[44] Bouillet C, Ciosmak D, Lallemant M, Laruelle C and Heizmann J 1997 Solid State Ionics 101-103 819

[45] Elliott R P 1960 Columbium-Oxygen system Trans. Am. Soc. Metals 52 990-1014

[46] Daccà A, Gemme G, Mattera L and Parodi R 1998 Appl. Surf. Sci. $\mathbf{1 2 6} 219$

[47] Bose A, Mondal P, Bhalerao G M, Kokil S V, Raghavendra S, Joshi S C, Srivastava A K and Tewari R 2020 Appl. Surf. Sci. $\mathbf{5 1 0} 145464$

[48] Veit R D, Kautz N A, Farber R G and Sibener S J 2019 Surf. Sci. 68863

[49] Nakagawa Y and Woods A D B 1963 Phys. Rev. Lett. 11271

[50] Dosch H, van Schwerin A. and Peisl J 1986 Phys. Rev. B 34 1654

[51] Rowe J M and Magerl A 1980 Phys. Rev. B 211706

[52] Dosch H and Peisl J 1985 Phys. Rev. B 32623

[53] Kurta R P, Bugaev V N, Stierle A and Dosch H 2008 J. Phys.: Condens. Matter 20275206

[54] Dosch H (ed) 1992 Critical Phenomena at Surfaces and Interfaces (Springer Tracts in Modern Physics vol 126) (Berlin: Springer)

[55] Semione G D L 2020 Niobium near surface composition relevant for superconducting radio-frequency cavities Dissertation Universität Hamburg

[56] Schober T 1973 Scr. Metall. 71119

[57] Schober T, Pick M A and Wenzl H 1973 Phys. Status Solidi 18 175

[58] Schober T 1975 Phys. Status Solidi 30107

[59] Nečas D and Klapetek P 2012 Gwyddion: an open-source software for SPM data analysis Cent. Eur. J. Phys. 10 181-8

[60] Manchester F D 2000 Phase Diagrams of Binary Hydrogen Alloys (Materials Park: ASM International)

[61] Maniscalco J T, Gonnella D and Liepe M 2017 J. Appl. Phys. 121043910

[62] Joshi A and Strongin M 1974 Scr. Metall. 8413

[63] Garg P, Balachandran S, Adlakha I, Lee P J, Bieler T R and Solanki K N 2018 Supercond. Sci. Technol. 31115007

[64] Wenskat M, Čižek J, Liedke M O, Butterling M, Bate C, Haušild P, Hirschmann E, Wagner A and Weise H 2020 Sci. Rep. 10

[65] Veit R D, Farber R G, Sitaraman N S, Arias T A and Sibener S J 2020 J. Chem. Phys. 152214703 